\section{Macular and peripapillary retinal nerve fibre layer thickness in patients with cyanotic congenital heart disease}

MC de Aguiar Remigio', CT Brandt², CCL Santos³, TE Arantes ${ }^{1}$ and MIR de Aguiar ${ }^{4}$

\begin{abstract}
Purpose To evaluate macular and retinal nerve fibre layer (RNFL) measurements in patients with cyanotic congenital heart disease (cCHD) using spectral domain optical coherence tomography (OCT). Patients and methods Thirty patients with cCHD (18 females and 12 males, mean age $\mathbf{1 0 . 9}$ years) and 60 healthy controls (35 females and 25 males, mean age $\mathbf{1 1 . 2}$ years) underwent complete ophthalmologic examination and OCT measurements of macular and peripapillary RNFL thickness. Results Patients with cCHD had significantly thinner measurements in all macular subfields compared with healthy controls $(P<0.001)$. There was no significant difference in peripapillary RNFL thickness between the two groups, with the exception of the upper quadrant, for which thickness measurements were higher in patients with cCHD $(P=0.021)$.

Conclusions Patients with cCHD showed a significant decrease in macular thickness and a thickened superior quadrant RNFL thickness when compared with healthy controls. This may represent the damage caused by the effect of hypoxia.
\end{abstract}

Eye (2015) 29, 465-468; doi:10.1038/eye.2014.330; published online 16 January 2015

\section{Introduction}

Congenital anomalies of the heart and great vessels are among the most frequent major congenital malformations. ${ }^{1,2}$ Cyanotic congenital heart disease (cCHD) is characterised by intracardiac right-to-left shunting of unsaturated blood and its distribution into the systemic circulation, resulting in arterial hypoxaemia. ${ }^{3,4}$

Strabismus, optic nerve hypoplasia and papilledema have been reported in patients with CHD, in addition to associations with ptosis and cataract. ${ }^{5-16}$ Congenital cardiac disorders have effects on the retinal vasculature, with a high prevalence of retinal vessel tortuosity and venous dilation. ${ }^{6-9,15,16}$

Blood flow to the optic nerve and the retina varies according to local metabolic demand. ${ }^{17,18}$ There is a close relationship between neural activity and levels of capillary perfusion, with loss of ganglion cells and thinning of the retinal nerve fibre layer (RNFL) in retinal ischaemia. ${ }^{19,20}$

Optical coherence tomography (OCT) is a noninvasive technique that performs high resolution in vivo imaging of retinal, choroidal and optic nerve head structures. It is a fundamental diagnostic tool used to monitor patients with glaucoma and macular disorders such as diabetic retinopathy. It allows the assessment of morphological changes in retinal structure to achieve a better understanding of several systemic disorders. ${ }^{21}$

The purpose of this study was to evaluate the macular and RNFL thickness in patients with cCHD.

\section{Materials and methods}

This was an observational cross-sectional study including 60 eyes of 30 cCHD subjects (group 1) and 120 eyes of 60 healthy subjects (group 2). The participants were recruited from the Pediatric Cardiology Service of the 'Instituto de
${ }^{1}$ Department of Ophthalmology, Fundação Altino Ventura, Recife, Brazil

${ }^{2}$ Department of Surgery, Universidade Federal de Pernambuco, Recife, Brazil

${ }^{3}$ Department of Pediatric Cardiology, Instituto de Medicina Integral Prof. Fernando Figueira, Recife, Brazil

${ }^{4}$ Department of Cardiology, Universidade Federal de Pernambuco, Recife, Brazil

Correspondence: MC de Aguiar Remigio, Department of Ophthalmology, Fundação Altino Ventura, Rua da Soledade, 170, 50070-040 Boa Vista, Recife, Pernambuco, Brazil Tel/Fax: +55 8133024300 . E-mail: ceciliaremigio@ uol.com.br

Received: 5 February 2014 Accepted in revised form: 7 December 2014 Published online: 16 January 2015 
Medicina Integral Professor Fernando Figueira, Recife, Brazil, and healthy controls were recruited from among the patients' relatives.

The study was approved by the Institute Ethics Committee and adhered to the principles of the Declaration of Helsinki. Informed consent was obtained from the parents or legal guardians of all patients prior to enrolment.

The inclusion criteria for all participants were a best-corrected visual acuity of 20/40 or better, spherical refraction within 5.0 dioptres (D) and cylinder correction within $3.0 \mathrm{D}$. The exclusion criteria were media opacities that could interfere with fundus imaging, history of glaucoma or other ocular disease that could affect retinal thickness measurements and any systemic disease, other than heart disease, that could cause hypoxaemia.

All patients underwent a full ophthalmological assessment at the Ophthalmology Service of the 'Fundação Altino Ventura, Recife, Brazil, including visual-acuity testing, evaluation of ocular alignment, intraocular pressure measurements, anterior and posterior segment biomicroscopy and indirect ophthalmoscopy.

\section{Instrumentation}

OCT scans were performed by a single skilled technician using a spectral domain-OCT (RTVue, version 4.0; Optovue Inc., Fremont, CA, USA). In this study, the EMM5 scan and RNFL thickness (3.45) protocols were used.

The EMM5 scan protocol consists of a grid-like scanning pattern with an outer $6 \mathrm{~mm} \times 6 \mathrm{~mm}$ area with 13 horizontal and 13 vertical scans of a $0.5 \mathrm{~mm}$ interval and an inner $4 \mathrm{~mm} \times 4 \mathrm{~mm}$ area with eight horizontal and eight vertical scans of a $0.5 \mathrm{~mm}$ interval. The scans produce maps consisting of concentric circles with diameters of 1, 3 and $5 \mathrm{~mm}$, providing an automatic thickness analysis for each of the nine early treatment diabetic retinopathy study (ETDRS) subfields. Each of the nine subfield measurements of the ETDRS-like map was recorded for all scans taken.

The RNFL scan pattern completes four circular scans in $0.16 \mathrm{~s}$ at a diameter of $3.45 \mathrm{~mm}$, targeted around the optic nerve head. The RNFL parameters studied were the average RNFL thickness and the RNFL thickness in each of four quadrants, defined as superior, nasal, inferior and temporal. The RNFL thickness of each quadrant and the average RNFL thickness were recorded.

Scans with signal strength indices $<45$, decentred images, segmentation errors or evidence of algorithm failure were not included in the analyses.

\section{Statistical analyses}

The IBM SPSS 20.0 statistics package was used for data analysis. Continuous variables are expressed as the mean $\pm S E M$, and categorical variables are expressed as absolute and relative frequencies. The $t$-test for unpaired samples calculation was used to analyse differences in age and spherical equivalent within groups. The $\chi^{2}$-test was used to verify the association between qualitative variables. For each subject, both eyes were enrolled in the study; generalised estimating equation models were generated to account for the correlation between eyes of the same patient. $P$-values $<0.05$ were considered to indicate statistical significance.

\section{Results}

The demographics and clinical characteristics of the study subjects are shown in Table 1 .

Twelve patients had undergone prior cardiac surgery without resolution of cyanosis. The distribution of cyanotic congenital heart lesions is shown in Table 2.

The ophthalmological findings of the cCHD subjects were as follow: conjunctival hyperaemia associated with vascular engorgement in 30 eyes of 15 patients, unilateral lenticular opacities that did not compromise the visual axis in two patients, unilateral peripalpebral fistula associated with obstruction of the lacrimal system and exotropia in one patient. No paresis or nystagmus was found. Data obtained from fundus examination showed retinal vascular tortuosity in all cCHD patients (100\% of eyes). No abnormality was found during the ophthalmological examination in group 2.

The macular thickness measurements in CCHD patients were thinner at all subfield areas of the ETDRS-like map in comparison with the healthy subjects (Table 3).

The RNFL thickness of the superior quadrant in the cCHD group was increased when compared with group $2(P=0.021)$. The RNFL measures within other quadrants

Table 1 Demographic and clinical characteristics of cyanotic congenital heart disease group (group $1, n=30$ subjects, 60 eyes) and healthy control group (group 2, $n=60$ subjects, 120 eyes)

\begin{tabular}{lrrr}
\hline & \multicolumn{1}{c}{ Group 1 } & \multicolumn{1}{c}{ Group 2 } & P-value \\
\hline Age(years), mean \pm SE & $10.9 \pm 5.1$ & $11.2 \pm 2.9$ & $0.766^{\mathrm{a}}$ \\
Male, $n(\%)$ & $12(40.0 \%)$ & $25(41.7 \%)$ & $0.880^{\mathrm{b}}$ \\
Female, $n(\%)$ & $18(60.0 \%)$ & $35(58.3 \%)$ & \\
Spherical equivalent & $-0.6 \pm 1.2$ & $-0.2 \pm 0.8$ & $<0.088^{\mathrm{a}}$ \\
Haemoglobin & $19.9 \pm 2.2$ & $\mathrm{NA}$ & \\
Haematocrit & $61.8 \pm 6.2$ & $\mathrm{NA}$ & \\
Saturation & $73.1 \pm 7.6$ & $\mathrm{NA}$ & \\
\hline
\end{tabular}

Abbreviations: NA, not applicable; SE, standard error.

${ }^{\text {a }} t$-test.

b $\chi^{2}$-test. 
Table 2 Distribution of congenital heart lesions

\begin{tabular}{lrr}
\hline & $\mathrm{n}$ & $\%$ \\
\hline Tetralogy of Fallot & 6 & 20.0 \\
Univentricular heart with pulmonary stenosis & 4 & 13.3 \\
Double-outlet right ventricle with pulmonary stenosis & 4 & 13.3 \\
VSD and pulmonary atresia & 4 & 13.3 \\
Univentricular heart with pulmonary atresia & 2 & 6.7 \\
Single ventricle with PAH & 2 & 6.7 \\
Congenitally corrected transposition with VSD and & 2 & 6.7 \\
pulmonary stenosis & & \\
Congenitally corrected transposition with VSD and & 2 & 6.7 \\
pulmonary atresia & & \\
Double outlet right ventricle with PAH & 1 & 3.3 \\
Ebstein's anomaly of the tricuspid valve & 1 & 3.3 \\
Hypoplastic right ventricle and atrial septal defect & 1 & 3.3 \\
Complete atrioventricular septal defect and pulmonary & 1 & 3.3 \\
stenosis & & \\
Total & 30 & 100 \\
\hline
\end{tabular}

Abbreviations: PAH, pulmonary arterial hypertension; VSD, ventricular septal defect.

Table 3 Macular thickness in group 1 and group 2

\begin{tabular}{lccc}
\hline & Group 1 & Group 2 & P-value \\
\hline Fovea & $187.0 \pm 4.4$ & $236.9 \pm 2.7$ & $<0.001$ \\
Inner temporal & $259.3 \pm 2.9$ & $304.7 \pm 1.8$ & $<0.001$ \\
Inner superior & $272.5 \pm 2.8$ & $322.5 \pm 1.8$ & $<0.001$ \\
Inner nasal & $269.6 \pm 3.2$ & $319.3 \pm 2.1$ & $<0.001$ \\
Inner inferior & $269.1 \pm 2.9$ & $316.0 \pm 1.7$ & $<0.001$ \\
Outer temporal & $227.0 \pm 3.8$ & $286.1 \pm 1.6$ & $<0.001$ \\
Outer superior & $246.1 \pm 3.6$ & $301.2 \pm 2.4$ & $<0.001$ \\
Outer nasal & $262.4 \pm 2.8$ & $313.3 \pm 1.8$ & $<0.001$ \\
Outer inferior & $236.2 \pm 3.3$ & $288.0 \pm 1.5$ & $<0.001$
\end{tabular}

Values expressed in micrometres as the mean \pm SEM (calculated by the GEE model)

Table 4 Peripapillary retinal nerve fibre layer thickness in group1 and group 2

\begin{tabular}{lrrr}
\hline & Group 1 & \multicolumn{1}{c}{ Group 2 } & P-value \\
\hline Mean RNFL & $117.6 \pm 2.6$ & $115.2 \pm 1.3$ & 0.430 \\
Temporal & $80.3 \pm 2.7$ & $82.0 \pm 1.3$ & 0.584 \\
Superior & $153.2 \pm 3.7$ & $142.9 \pm 2.4$ & 0.021 \\
Nasal & $90.2 \pm 4.4$ & $85.6 \pm 1.7$ & 0.332 \\
Inferior & $146.3 \pm 4.7$ & $148.6 \pm 2.3$ & 0.658 \\
\hline
\end{tabular}

Values expressed in micrometres as the mean \pm standard error of the mean (calculated by the GEE model).

and the average RNFL thickness were not significantly different between the study groups (Table 4).

\section{Discussion}

In $\mathrm{CCHD}$, the major pathophysiological aspect is the presence of hypoxia due to poor arterial saturation.
It is not solely a congenital cardiac malformation but a multisystem systemic disorder affecting several organs and tissues, including the visual system.22 This cross-sectional study presents, to our knowledge, the first retinal thickness measurements obtained with an SD-OCT system in cCHD patients.

Previous studies of the ocular circulation have shown that congenital cardiac disorders may affect the retinal vasculature related to hypoxia and polycythaemia. ${ }^{6-8,15}$ Our data showed that retinal vascular tortuosity and venous dilatation in all patients with $\mathrm{CCHD}$, which also resulted in high haematocrit and low oxygen saturation. This may corroborate the hypothesis predicted by other authors. ${ }^{6,8}$

The present study found a lower frequency of ocular abnormalities than previous reports, most likely due to the lack of genetic disorders associated with this sample. Previous studies of CHD subjects and associated syndromes have shown a large percentage of ocular findings, such as optic nerve hypoplasia, coloboma of the optic disc or choroid, congenital glaucoma and strabismus. ${ }^{6,11,14}$ This may be related to a possible embryologic link between the ocular and cardiac defects. ${ }^{6}$ It is also important to add that many patients die at very early age with congenital heart disease, hence there is selection for the milder cases that survive.

A significant thinning in the central macula and the macular subfields was present in CCHD patients. These findings may represent the damage caused by the low oxygen supply because haemodynamic regulation is essential for the structural and functional integrity of the retina. ${ }^{18-20}$ Diabetic patients with minimal diabetic retinopathy as well as sickle cell patients also suffer from vascular damage in the retinal tissue with significant thinning in the central macula and parafoveal regions on OCT images. ${ }^{23,24}$

It was also observed that the peripapillary RNFL in the cCHD group was significantly thicker in the superior quadrant in comparison with the control group. Recent evidence suggest that the superior and inferior temporal blood vessels make a direct contribution to the OCT RNFL thickness ${ }^{25}$ and retinal vascular abnormalities in cCHD patients may lead to artefacts in RNFL thickness measurements. ${ }^{26}$

Because this was a case-control study, to further evaluate the influence of time on disease evolution, longitudinal studies should be performed because the retinal damage is most likely progressive. Our study was also restricted to structural analysis, therefore, future research should address the impact of these findings on visual function. Another limitation is that a large number of retinal thickness parameters were analysed, which may have increased the chance of a type I error 
during hypothesis testing, and some of the differences detected may have occurred simply by chance.

Our findings agree with the hypothesis that systemic haemodynamic alterations in patients with CCHD, secondary to hypoxia, may lead to structural abnormalities in the retina. ${ }^{7}$

In conclusion, patients with cCHD showed a significant decrease in macular thickness and a thickened superior quadrant RNFL thickness when compared with healthy controls. This finding supports the hypothesis that damage to the retina may result from systemic hypoxaemia, leading to structural abnormalities that are, at least partially, responsible for the measurements observed by OCT.

\section{Summary}

\section{What was known before}

- Numerous studies of the ocular circulation have shown that congenital cardiac disorders may have effects on the retinal vasculature (retinal vascular tortuosity and venous dilation). Some ophthalmologic findings have been described as strabismus, optic nerve hypoplasia, amblyopia, ptosis and congenital cataract.

\section{What this study adds}

- To our knowledge, this is the first reported quantitative comparison of retinal thickness measurements obtained with a spectral domain optical coherence tomography in patients with cyanotic congenital heart disease.

\section{Conflict of interest}

The authors declare no conflict of interest.

\section{References}

1 Hoffman JIE, Kaplan S. The incidence of congenital heart disease. J Am Coll Cardiol 2002; 39(12): 1890-1900.

2 Reller MD, Strickland MJ, Riehle-Colarusso T, Mahle WT, Correa A. Prevalence of congenital heart defects in metropolitan Atlanta, 1998-2005. J Pediatr 2008; 153(6): 807-813.

3 Friedman AH, Fahey JT. The transition from fetal to neonatal circulation: normal responses and implications for infants with heart disease. Semin Perinatol 1993; 17(2): 106-121.

4 Rudolph AM. The changes in the circulation after birth. Their importance in congenital heart disease. Circulation 1970; 41(2): 343-359.

5 Larned DC, Flanagan JC, Nelson LE, Harley RD, Wilson TW. The association of congenital ptosis and congenital heart disease. Ophthalmology 1986; 93(4): 492-494.

6 Mansour AM, Bitar FF, Traboulsi EI, Kassak KM, Obeid MY, Megarbane A et al. Ocular pathology in congenital heart disease. Eye (Lond) 2005; 19(1): 29-34.

7 Johns KJ, Johns JA, Feman SS. Retinal vascular abnormalities in patients with coarctation of the aorta. Arch Ophthalmol 1991; 109(9): 1266-1268.
8 Tsui I, Shamsa K, Perloff JK, Lee E, Wirthlin RS, Schwartz SD. Retinal vascular patterns in adults with cyanotic congenital heart disease. Semin Ophthalmol 2009; 24(6): 262-265.

9 VanderVeen DK, Pasquale LR, Fulton AB. Central retinal vein occlusion in a young child with cyanotic heart disease. Arch Ophthalmol 1997; 115(8): 1077.

10 Stirn Kranjc B. Ocular abnormalities and systemic disease in Down syndrome. Strabismus 2012; 20(2): 74-77.

11 Ming JE, Russell KL, Bason L, McDonald-McGinn DM, Zackai EH. Coloboma and other ophthalmologic anomalies in Kabuki syndrome: distinction from charge association. Am J Med Genet A 2003; 123A(3): 249-252.

12 Flammer J, Konieczka K, Bruno RM, Virdis A, Flammer AJ, Taddei S. The eye and the heart. Eur Heart J 2013; 34(17): 1270-1278.

13 Bianca S, Barrano B, Barone C, Cataliotti A, Indaco L, Boemi G et al. Congenital cataract and heart septal defects: are contiguous or reciprocally influenced genes involved? Congenit Heart Dis 2009; 4(3): 196-197.

14 Chen SC, D'Souza N. Familial tetralogy of Fallot and glaucoma. Am J Med Genet 1990; 37(1): 40-41.

15 Mojtaba Golzan S, Leaney J, Cordina R, Avolio A, Celermajer DS, Graham SL. Spontaneous retinal venous pulsatility in patients with cyanotic congenital heart disease. Heart Vessels 2012; 27(6): 618-623.

16 Goel N, Kumar V, Seth A, Ghosh B. Proliferative retinopathy in a child with congenital cyanotic heart disease. J AAPOS 2010; 14(5): 455-456.

17 Garhofer G, Werkmeister R, Dragostinoff N, Schmetterer L. Retinal blood flow in healthy young subjects. Invest Ophthalmol Vis Sci 2012; 53(2): 698-703.

18 Flammer J, Mozaffarieh M. Autoregulation, a balancing act between supply and demand. Can J Ophthalmol 2008; 43(3): 317-321.

19 Neufeld AH, Kawai SI, Das S, Vora S, Gachie E, Connor JR et al. Loss of retinal ganglion cells following retinal ischemia: the role of inducible nitric oxide synthase. Exp Eye Res 2002; 75(5): 521-528.

20 Caprara C, Grimm C. From oxygen to erythropoietin: relevance of hypoxia for retinal development, health and disease. Prog Retin Eye Res 2012; 31(1): 89-119.

21 Adhi M, Duker JS. Optical coherence tomography-current and future applications. Curr Opin Ophthalmol 2013; 24(3): 213-221.

22 Perloff JK. Cyanotic congenital heart disease is a multisystem systemic disorder. Exp Clin Cardiol 1999; 4(2): 77-79.

23 Van Dijk HW, Kok PHB, Garvin M, Sonka M, Devries JH, Michels RPJ et al. Selective loss of inner retinal layer thickness in type 1 diabetic patients with minimal diabetic retinopathy. Invest Ophthalmol Vis Sci 2009; 50(7): 3404-3409.

24 Hoang QV, Chau FY, Shahidi M, Lim JI. Central macular splaying and outer retinal thinning in asymptomatic sickle cell patients by spectral-domain optical coherence tomography. Am J Ophthalmol 2011; 151(6): 990-994.e1.

25 Hood DC, Salant JA, Arthur SN, Ritch R, Liebmann JM. The location of the inferior and superior temporal blood vessels and interindividual variability of the retinal nerve fibre layer thickness. J Glaucoma 2010; 19(3): 158-166.

26 Hood DC, Fortune B, Arthur SN, Xing D, Salant JA, Ritch R et al. Blood vessel contributions to retinal nerve fibre layer thickness profiles measured with optical coherence tomography. J Glaucoma 2008; 17(7): 519-528. 